HABITAT UTIIIZATION, INTERSPECIFIC INTERACTIONS, AND STATUS OF A RECOLONIZED POPULATION OF BIGHORN SHEEP

AT A WILDHORSE RANGE

\title{
Kevin Coates
}

and

Sanford Schemnitz

Department of Fishery and Wildlife Sciences

New Mexico State University

Las Cruces

\section{Progress Toward Objectives}

1. Capture Work: We immobilized a 6-year old ram with $2.0 \mathrm{cc}$ of a $2: 1$ mixture of ketamine/xylazine hydrochloride. Induction time was 5.5 minutes. The ram was immobilized for 1 hour 56 minutes. A local DVM assisted with captures, and we administered the prophylactic injections previously described.

Two additional captures will be made for the purpose of radio-telemetry and physical examination. Future immobilizations will be made with ketamine/xylazine hydrochloride, using the antagonist yohombine as a reversal agent.

2. Population Estimates and Herd Composition: Between September 3 and November 30 , a total of 372 sheep (duplicate count) were located and classified. Overall classifications included $35.8 \%$ adult females, $33.6 \%$ lambs. $11.8 \%$ yearling females, $18.3 \%$ rams, and $0.5 \%$ unclassified females. We estimate the population to contain between 38 and 42 animals.

During the above period we observed and classified 65 groups of sheep. Mean group size was 5.7 animals (Figure 1). Group size ranged from 1 to 19 animals. Standard deviation was 4.8 sheep/group.

3. General Health of the Herd: Indices used to evaluate population quality during this period include physical condition and intensity of ram interactions. The physical condition of all sheep observed was good, with only minor variations between age/sex classes. Yearling females and rams over 4 years of age were in the best condition, while lactating ewes and juvenile rams tended toward medium condition. The inferior condition of lactating ewes and juvenile rains probably was due to the respective demands of gestation, lactation, and body growth.

Ram interactions were frequent and aggressive during this period. Behaviors exhibited by rams included mounts, chases, front kicks, neck fights, bites, lip-curls, hom displays, threat jumps, and charges to butt and clash (motor 


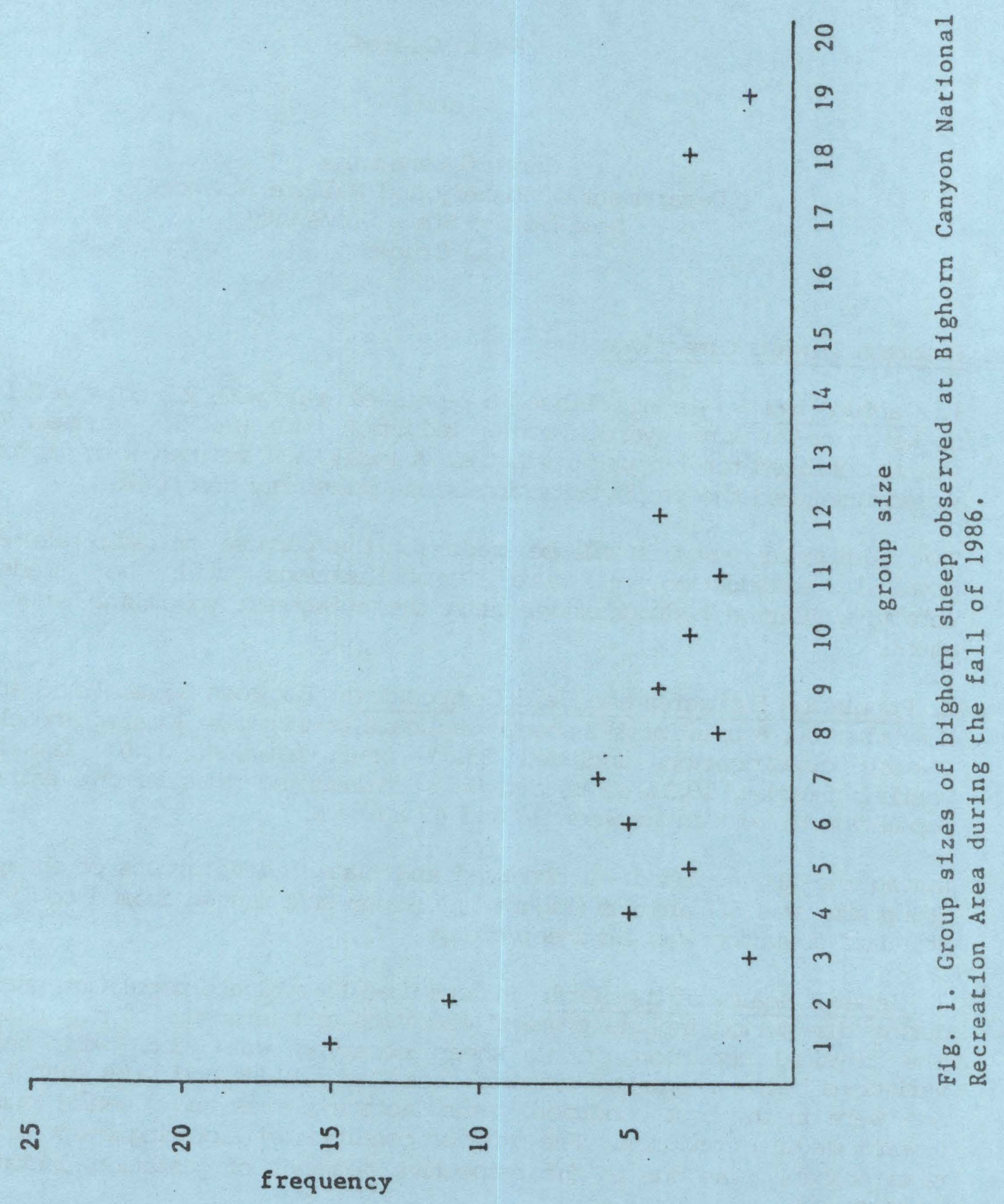


patterns according to Geist 1971). During a 5 minute period a 6-year ald ram initiated 1 bite, 2 butts, 1 mount, 1 neck fight, and 3 front kicks toward a 3-year old ram. In a different observation a 6-year old ram initiated 6 front kicks and one neck fight toward a 4-year old ram during 6 minutes.

Ram/ewe interactions were first observed October 27 and were intense throughout the remainder of this period. On November 19 we observed a 6-year old ram chase a radio-collared ewe as she attempted to forage; the ewe accomplished 3.8 minutes of foraging during a 46 minute period. A 4-year old ram was present during this interaction and despite being chased and butted by the 6-year ald ram it succeeded in mounting the ewe 3 times. After smelling the ewe's urine the 6-year old male exhibited a $30+$ second lip-curl.

Direct physical examination was made of the ram we captured for the purpose of radio-telemetry. Blood was drawn and will be tested for parsinfluenza 3*, blue-tongue, brucellosis, and soremouth. Ear scrapings were collected and will be examined for psoroptic mites. Tests for bacteriological titers and pasturella hemolytica type-t from nose and throat cultures respectively were negative. Fecal tests for lungworm were low/insignificant (12epg.).

4. Food Habits: Three ewe fecal collections were obtained. Rams associated with ewe groups extensively during the period and separate fecal collections were not made. Fecal collections were obtained from 2 groups of wild horses located within the abserved distribution of sheep. Replicate data will be generated by the analysis of 2 fecal collections obtained from ewe groups. Replicate data will be generated by tha analysis of 2 fecal collections obtained from wild horses.

We observed heavy utilization of curl-leaf mountain mahogany (Cercocarpus ledifolius); all preliminary data indicate that mountain mahogany is a key forage species for sheep at BICA. We also observed heavy utilization of wheatgrass (Agropyron spp.), and rubber rabbitbrush (Chrysothamnus nauseousus).

5. Foraging Behavior: The foraging behavior of ewes was analyzed in 2

habitats: habitat used in common with horses (non-precipitious locations greater than $400 \mathrm{~m}$ from the road), and habitat used in common with horses and/or humans (roadside locations). The foraging behavior of rams was analyzed separately for rams foraging in association with wild horses, and for rams in association with conspecifics. Thirty minutes of foraging behavior were analyzed in each situation.

Average foraging efficiencies of ewes were highest in habitat used in com mon with horses and lowest in habitat used in common with horses and/or humans. Average foraging efficiencies (FE) of ewes at non-precipitous areas greater than 400 meters (one-quarter mile) from the road were 99.7 and $99.3 \% \mathrm{FE}$ for 2 blocks of five 3 minute foraging periods. Standard deviations were 1.3 and 1.8 seconds of foraging per 15 minute block. Overall the mean FE (mean of the means) was $99.5 \%$ in habitat that ewes used in com mon with horses (Table 1).

Average foraging efficiencies at roadside locations were 59.3 and $96.6 \% \mathrm{FE}$ for blocks of five 3 minute foraging periods. Standard deviations were 8.2 and 59.3 
Table 1. Foraging efficiency of ewes in habitat used in common with wild horses (non-precipitous areas greater than 400 meters from the road) during fall.

\begin{tabular}{|c|c|c|c|c|c|c|}
\hline \multirow[b]{2}{*}{ Date } & \multirow[b]{2}{*}{ Time } & \multicolumn{3}{|c|}{ Time per Behavior (sec) } & \multirow[b]{2}{*}{ FE\& 8} & \multirow[b]{2}{*}{ FEX } \\
\hline & & Foraging & Social & Alert & & \\
\hline $11 / 5$ & $\begin{array}{l}1555-58 \\
1558-01 \\
1601-04 \\
1604-07 \\
1607-10\end{array}$ & $\begin{array}{l}180 \\
180 \\
180 \\
177 \\
180\end{array}$ & $\begin{array}{l}0 \\
0 \\
0 \\
0 \\
0\end{array}$ & $\begin{array}{l}0 \\
0 \\
0 \\
3 \\
0\end{array}$ & $\begin{array}{c}100.08 \\
100.08 \\
100.0 \\
98.3 \\
100.0\end{array}$ & 99.68 \\
\hline $11 / 26$ & $\begin{array}{l}1403-06 \\
1406-09 \\
1409-12\end{array}$ & $\begin{array}{l}180 \\
176 \\
180\end{array}$ & $\begin{array}{l}0 \\
0 \\
0\end{array}$ & $\begin{array}{l}0 \\
4 \\
0\end{array}$ & $\begin{array}{r}100.0 \\
97.8 \\
100.0\end{array}$ & 99.3 \\
\hline
\end{tabular}

FE $\%$ percent of $3 \mathrm{~min}$ interval devoted to foraging

FE X percent of $15 \mathrm{~min}$ block devoted to foraging 
seconds of foraging per 15 minute block. Overall the mean FE was $77.9 \%$ in habitat that ewes used in common with horses and/or humans (Table 2).

Average foraging efficiencies of rams were highest when they foraged in association with horses and lowest when not associated with horses. Average foraging efficiencies of rams in association with horses were 100.0 and $100.0 \%$ FE. Standard deviation was 0 seconds of foraging per 15 minute block. Overall the mean FE was $100.0 \%$ for rams foraging in association with horses (Table 3).

Average foraging efficiencies of rams not associated with wild horses were 81.2 and $98.9 \% \mathrm{FE}$ for blocks of five 3 minute foraging periods. Standard deviations were 2.8 and 62.4 seconds of foraging per 15 minute block. Overall the mean FE was $90.1 \%$ for rams foraging without association with horses (Table 4).

Ewes devoted a total of 5.2 minutes to alert behavior during 30 minutes of foraging at the roadside. The time spent in alert behavior ranged from 0 to 5.2 minutes per 15 minute block. On the average, 2.6 minutes were devoted to alert behavior per 15 minutes of foraging in habitat that ewes used in common with horses and/or humans.

Ewes spent a total of 1.1 minutes in social behavior during 30 minutes of foraging at the roadside. The time spent in social behavior ranged from 0.2 to 0.9 minutes per 15 minute block. On the average 0.6 minutes were devoted to social behavior per 15 minutes of foraging in habitat that ewes used in com mon with horses and/or humans.

Ewes did not devote any time to social behavior during 30 minutes of foraging in non-precipitious areas greater than 400 meters from the road. Ewes devoted a total of 11.3 minutes to social behavior during 30 minutes of foraging in habitat used in common with horses. On the average 5.6 minutes were devoted to social behavior per 15 minutes of foraging in habitat that ewes used in common with horses.

6. Habitat Utilization: Sheep were located a total of 60 times in research conducted to analyze habitat utilization. Habitat utilization was analyzed separately for ewe groups with lambs, ewe groups without lambs, groups of mixed age/sex composition, rams in association with horses, and rams not associated with honses. Sheep used 2 vegetation types.

Ewe groups with la mbs were located a total of 29 times in 2 vegetation types: 24 times (82.8\%) in Utah juniper/mountain mahogany woodland (Ju/Cele), and 5 times (17.2\%) in Utah juniper woodland (Juos). Ewe groups without lambs were located 3 times: 2 times (66.7\%), in Ju/Cele, and 1 time (33.3\%) in Juos. All observations $(n=15)$ of groups of mixed sex/age composition were in Ju/Cele.

Rams in association with horses were located 7 times in 2 vegetation types: 6 times $(85.7 \%)$ in Juos, and 1 time $(14.3 \%)$ in Ju/Cele. Rams not associated with horses were located 6 times in 2 vegetation types: 5 times (83.3\%) in Ju/Cele, and 1 time $(16.7 \%)$ in Juos. 
Table 2. Foraging efficiency of ewes in habitat used in comon with horses and/or humans (within 50 meters of the road) during the fall.

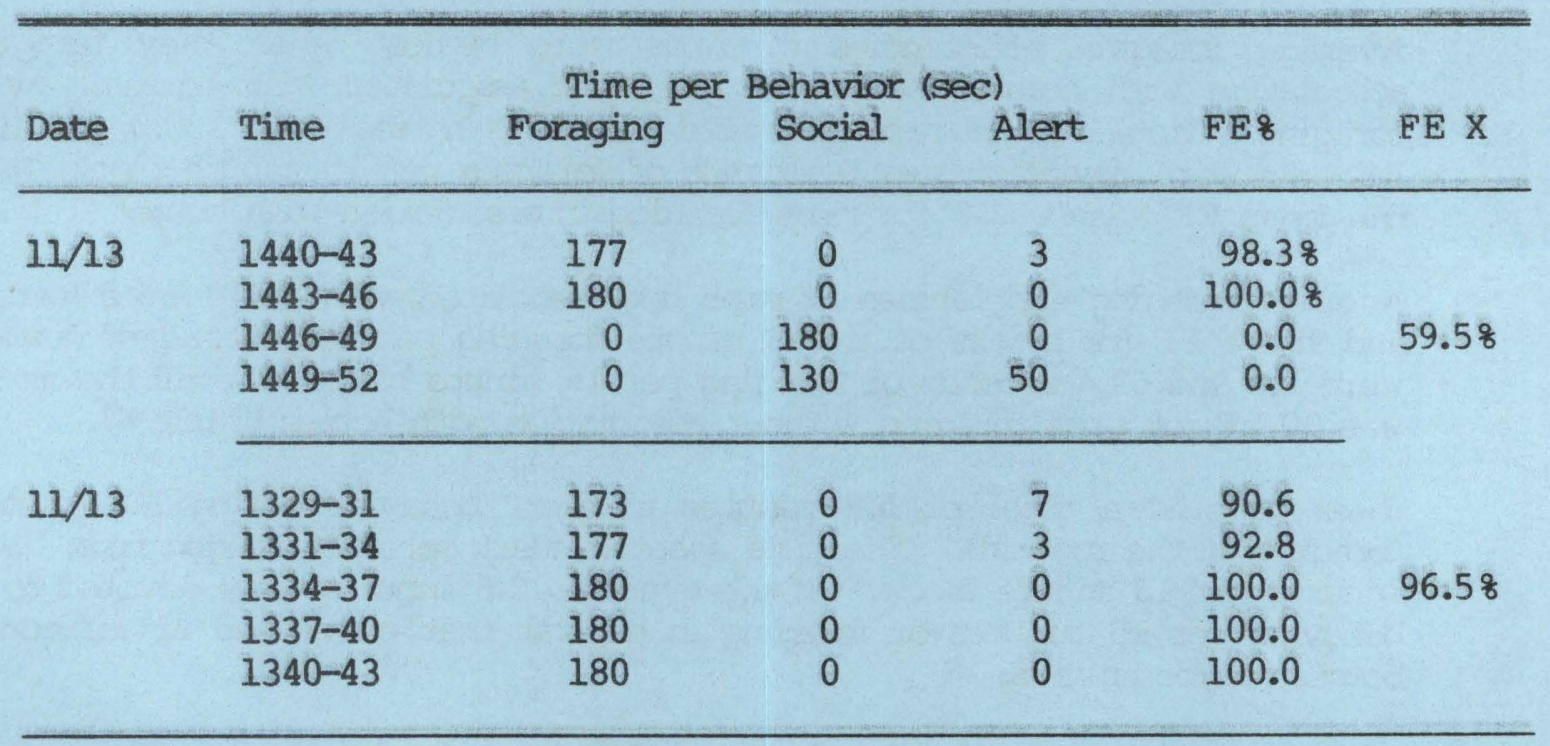

FE 8 percent of $3 \mathrm{~min}$ interval devoted to foraging

FE X percent of $15 \mathrm{~min}$ block devoted to foraging 
Table 3. Foraging efficiency of rams in association with horses during the fall.

\begin{tabular}{|c|c|c|c|c|c|c|}
\hline Date & Time & $\begin{array}{l}\text { Time per } \\
\text { Foraging }\end{array}$ & $\begin{array}{l}\text { Behavior } \\
\text { Social }\end{array}$ & c) & $\mathrm{FE} 8$ & FE X \\
\hline $11 / 17$ & $\begin{array}{l}1615-18 \\
1618-21 \\
1621-24 \\
1624-27 \\
1627-30\end{array}$ & $\begin{array}{l}180 \\
180 \\
180 \\
180 \\
180\end{array}$ & $\begin{array}{l}0 \\
0 \\
0 \\
0 \\
0\end{array}$ & $\begin{array}{l}0 \\
0 \\
0 \\
0 \\
0\end{array}$ & $\begin{array}{l}100.08 \\
100.08 \\
100.0 \\
100.0 \\
100.0\end{array}$ & 100.08 \\
\hline $11 / 25$ & $\begin{array}{l}1338-41 \\
1341-44 \\
1344-47 \\
1347-50 \\
1350-53\end{array}$ & $\begin{array}{l}180 \\
180 \\
180 \\
180 \\
180\end{array}$ & $\begin{array}{l}0 \\
0 \\
0 \\
0 \\
0\end{array}$ & $\begin{array}{l}0 \\
0 \\
0 \\
0 \\
0\end{array}$ & $\begin{array}{l}100.0 \\
100.0 \\
100.0 \\
100.0 \\
100.0\end{array}$ & 100.08 \\
\hline
\end{tabular}

FE: percent of $3 \mathrm{~min}$ interval devoted to foraging

FE X percent of $15 \mathrm{~min}$ block devoted to foraging 
Table 4. Foraging efficiency of rams in association with conspecifics during the fall.

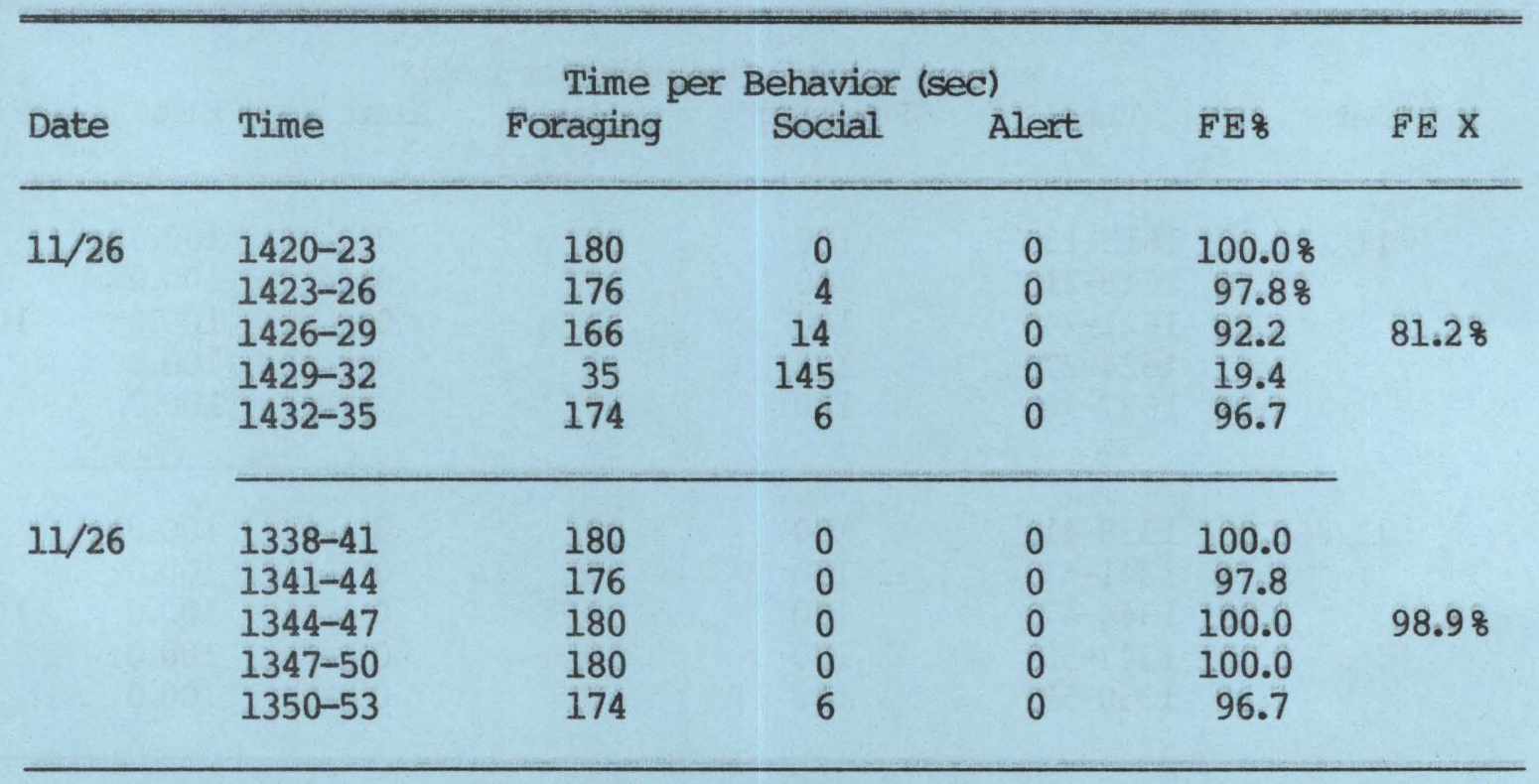

$\mathrm{FE}:$ percent of $3 \mathrm{~min}$ interval devoted to foraging

FE X percent of $15 \mathrm{~min}$ block devoted to foraging 
7. Activity and Habitat Utilization: Sheep behavior was analyzed during all daylight hours; 207 observations were recorded at half hour intervals (Figure 2). Behavior of sheep is not independent due to their gregarious social structure. We recorded the activity in which the majority of adult group members were involved.

Figure 2 is a graphical representation of the 3 behavions most frequently observed which were of relatively long duration: foraging, moving, and resting. According to our sampling design, activity was recorded at half-hour intervals; graphical representation of relatively short duration behaviors is misleading.

Sheep were observed foraging during all daylight hours and foraging comprised $50 \%$ or more of the activity from 0700 to 1100 , and from 1230 to 1700 . Moving comprised $25 \%$ or more of the activity from 0700 to 0730 , and from 1700 to 1730. Sheep were also observed resting during all daylight hours and resting comprised $40 \%$ or more of the activity from 0730 to 8000 , and from 1030 to 1230.

8. Total habitat Potential: Vegetative associations were not analyzed during the fall data collection season due to time needed for proposal preparation. Preferred foraging areas were identified. Vegetation of these areas is adequately represented by data collected during the summer. 

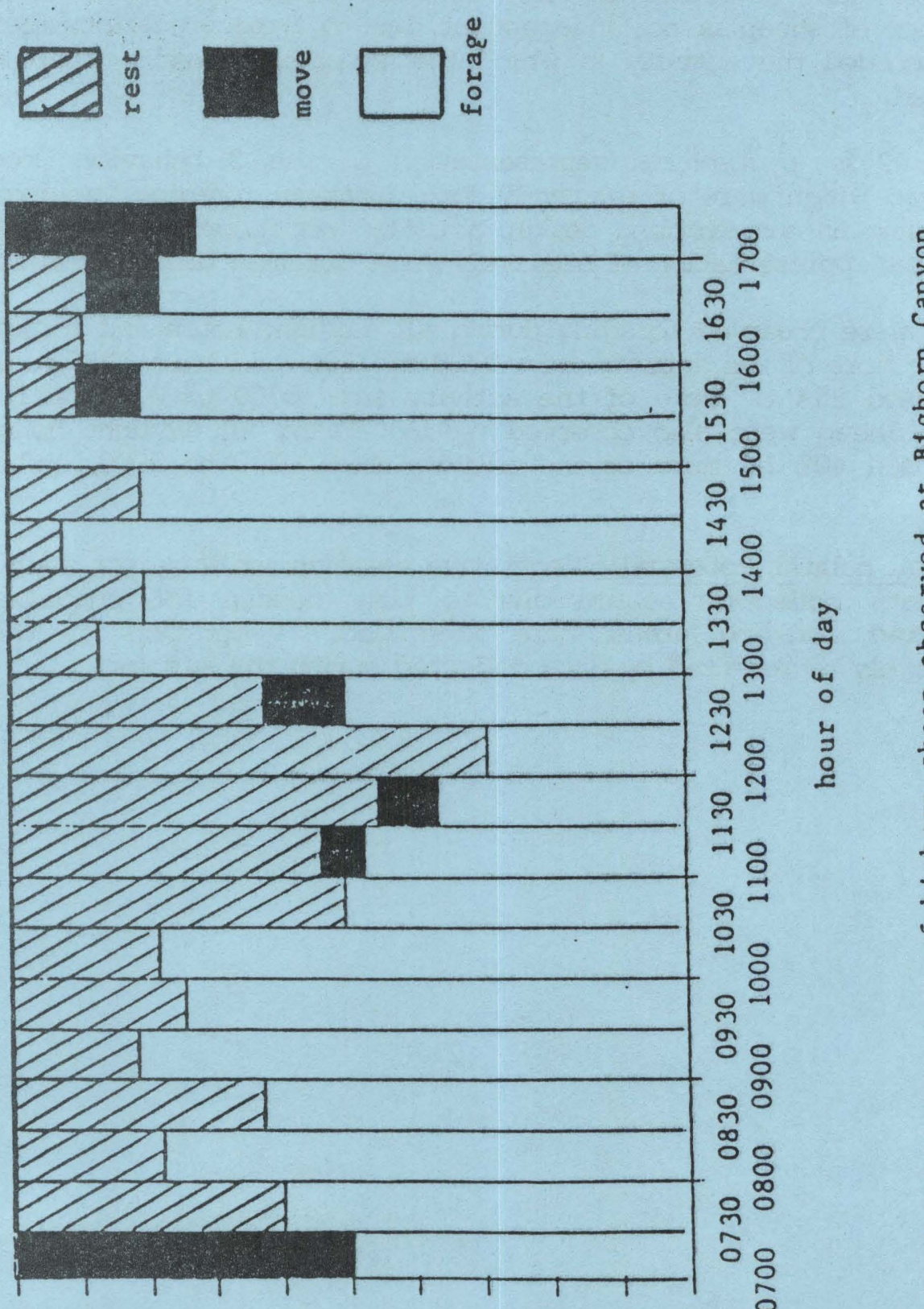

的

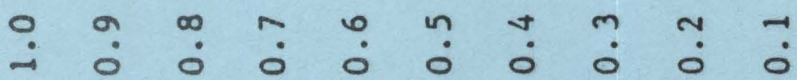

frequncy of observation 